\title{
Reforma concursal y medidas introducidas por el legislador para conseguir un sistema eficiente ${ }^{1}$
}

\author{
Enrique Gadea Soler \\ Profesor titular de Derecho Mercantil \\ Universidad de Deusto
}

\begin{abstract}
Resumen: La nueva Legislación concursal española aprobada en 2003 ha venido a satisfacer una aspiración largamente sentida en el derecho patrimonial español. La obsoleta y dispersa regulación anterior favorecía que tuviésemos un sistema ineficiente, entre otras cosas, porque ni siquiera constituía un todo armónico con unos objetivos claramente definidos. En la reciente Ley Concursal, el legislador define el fin del concurso, que no es otro que el pago a los acreedores, inclinándose para su consecución por la conservación de la empresa antes que por su liquidación. El objetivo de este trabajo es analizar las medidas introducidas por el legislador para conseguir el fin marcado. Para ello, el artículo comienza tratando la cuestión del momento temporal adecuado para la apertura del procedimiento y después de abordar aspectos como el régimen orgánico, los efectos del concurso o el sistema de privilegios, finaliza con la referencia a la regulación del procedimiento abreviado.
\end{abstract}

Palabras clave: Reforma del procedimiento concursal.

Abstract: The new Spanish Insolvency Legislation, approved in 2003, has met a long-standing need in Spanish Patrimonial Law. The previous obsolete and indistinct regulation meant that our system was an inefficient one because, among other things, it did not even constitute a whole that was in harmony with clearly defined objectives. The legislator defines the aim of bankruptcy proceedings in the recent Insolvency Law: that of paying creditors, for which means there is a tendency towards saving the company in priority to winding it up. The aim of this study is to analyse the measures introduced by the legislator in order to achieve its purpose. Therefore, the article begins by dealing with the question of the suitable provisional moment for opening proceedings, goes on to discuss matters such as the organic system, the effects of bankruptcy proceedings and the system of privileges, and ends with reference to regulation of the abridged proceedings.

Key words: Bankruptcy proceedings reform.

1 Estudio presentado en la Universidad Internacional Menéndez Pelayo de Santander, el 9 de agosto de 2005, en el Seminario: Administración de justicia. Nuevas tecnologías y reformas procesales, dirigido por Dionisio Mantilla y José Almagro Nosete. 
Sumario: I. La reforma concursal: referencia a los fines y caracteres de la nueva regulación. - II. Medidas introducidas por el legislador para conseguir un sistema eficiente: 1. Momento temporal de la apertura del procedimiento. 2. Novedades en la estructura orgánica del concurso: simplificación de la misma y creación de los Juzgados de lo Mercantil. 3. Regulación sistemática de los efectos del concurso. 4. Revisión del sistema de privilegios. 5. Admisión de propuesta anticipada de convenio. 6. Agilización de la fase de liquidación. 7. Regulación de un procedimiento abreviado.

\section{La reforma concursal: referencia a los fines y caracteres de la nueva regulación}

Con la aprobación, el 9 de julio de 2003, de la Ley Concursal y de la Ley Orgánica para la Reforma Concursal se ha satisfecho una aspiración largamente sentida en el derecho patrimonial español, como es la reforma de la legislación concursal.

Nuestra legislación precedente adolecía de múltiples defectos como arcaísmo, inadecuación a la realidad social y económica de nuestro tiempo, dispersión, carencia de un sistema armónico, predominio de intereses particulares en detrimento de otros generales y del principio de igualdad de tratamiento de los acreedores, etc., lo que conllevaba que tuviésemos un sistema ineficiente ${ }^{2}$.

Por eso, toda la reforma está al servicio de la eficiencia que no pudo verse cumplida con la regulación concursal derogada, es decir, se trata de que con el nuevo sistema los acreedores puedan ver satisfechos sus créditos en la mayor proporción y en el menor tiempo posibles, dado que con la Ley Concursal, utilizando las palabras de la profesora J. Pulgar ${ }^{3}$, «se superan ... esas tendencias reformistas del Derecho concursal frecuentes en la doctrina y reformas europeas en torno a los años 80 que, atribuyeron a los procedimientos concursales una función sanatoria que, en ocasiones - como la reforma francesa de 1984-, se anteponía incluso a la finalidad satisfactiva de los intereses crediticios de los acreedores».

Esta Ley, ante el fracaso de las políticas «sanatorias» y siguiendo la tendencia manifestada en actuales reformas, se asienta sobre la idea de pago a los acreedores, inclinándose para la consecución de ese objetivo por la solución conservativa antes que por la liquidación. El legislador es consciente que la conservación no sólo evita la destrucción del valor em-

${ }^{2}$ Una referencia a esta cuestión puede verse en Rojo, A., «La Reforma del Derecho Concursal español», en La Reforma de la Legislación concursal, Madrid, 2003, pp. 92 y ss.

3 «La aprobación de la reforma concursal en el pleno del Congreso: ¿cambio de sentido de la reforma?», en Actualidad jurídica Aranzadi, n. ${ }^{\circ}$ 578, 22 de mayo de 2003, pp. 3 у 4. 
presarial que toda liquidación conlleva, sino que, además, constituye el mejor modo de que los acreedores vean satisfechos sus legítimos derechos crediticios. Aunque el objeto del concurso no sea el saneamiento de empresas, un convenio de continuación puede ser el instrumento para salvar las que se consideren total o parcialmente viables, en beneficio no sólo de los acreedores, sino del propio concursado, de los trabajadores y de otros intereses (Exposición de Motivos de la Ley 2/2003, VI).

Los caracteres que presiden la vigente Legislación recogen las viejas reivindicaciones y anhelos de la doctrina, que, junto a la reducción de privilegios a la que me referiré posteriormente, consideraba imprescindible la unidad legal, la unidad de disciplina y la unidad y flexibilidad de procedimiento.

\section{A) Unidad legal}

Con la regulación en un solo texto de los aspectos procesales y materiales, con la única excepción de las normas que por su naturaleza han exigido el rango de Ley Orgánica y de la legislación concursal especial dictada para las crisis de las entidades de crédito, de inversión y de seguro (Disposición adicional 2. ${ }^{\circ} \mathrm{LC}$ ), se pretende - por lo menos, en gran parte - acabar con la dispersión actual y conseguir que el sistema concursal español pueda ser calificado como un auténtico ordenamiento. De esa forma, se pretende romper con los viejos dogmatismos del siglo XIX, que tanto han contribuido a la descoordinación del sistema concursal y acabar con las disposiciones legales, surgidas con el paso del tiempo, en las que se privilegia el tratamiento de determinados créditos o se especifica el alcance de la declaración concursal sobre determinados contratos que tienen regulación especial.

\section{B) Unidad de disciplina}

La existencia de instituciones concursales distintas para el tratamiento de las situaciones de insolvencia en función de si el deudor es o no comerciante, se justificaba por el mayor rigor con el que éste era tratado. Como ha señalado el profesor Galgano ${ }^{4}$ : «El ius mercatorum instaura el rigor más despiadado ante el comerciante que se halla en estado de insolvencia. La grave represión penal y las infamantes consecuencias personales de la quiebra, muestran el precio que estuvo dispuesta a pagar la clase mercantil para adquirir crédito y gozar de la confianza del mercado». Sin embargo, la desaparición del carácter represivo de la insolvencia mercantil, ha per-

${ }^{4}$ En Historia del Derecho mercantil, Barcelona, 1980 -Storia del Diritto commerciale, trad. cast. BisBAL, J. - , pp. 37 y ss. 
mitido unificar el procedimiento, sin perjuicio de que existan determinadas especialidades aplicables en el caso de que el deudor sea empresario.

\section{C) Unidad y flexibilidad de procedimiento}

La unidad de procedimiento, que recibe el nombre de concurso, es posible gracias a la flexibilidad con que la Ley lo configura. Ello supone que se inicia cuando concurre uno de los presupuestos legales previstos y a partir de ese momento, tras una fase común, que se abre con la declaración de concurso y concluye una vez presentado el informe de la administración concursal y transcurrido el plazo de impugnaciones o resueltas las formuladas contra el inventario o contra la lista de acreedores, se pasará a otra alternativa, dado que la satisfacción de los acreedores, en función de las circunstancias, puede obtenerse, como ya advertíamos anteriormente, por la vía liquidatoria o por convenio. Incluso, se ha previsto la posibilidad de utilizar un procedimiento abreviado, al que me referiré posteriormente, para abordar los concursos de escasa entidad.

\section{Medidas introducidas por el legislador para conseguir un sistema eficiente}

No puede ponerse en duda que nos encontramos ante una ambiciosa reforma del sistema concursal que determina el tránsito de un Derecho concursal arcaico a un Derecho concursal moderno y ágil, que sigue las tendencias de las reformas europeas más modernas, y, en particular, de los modelos alemán e italiano. El tiempo dirá si los resultados prácticos son o no satisfactorios, aunque es cierto que se ha realizado un gran esfuerzo para conseguir la anhelada eficiencia. Precisamente, voy a dedicar el apartado siguiente a tratar las medidas más importantes previstas por el legislador para conseguir ese objetivo:

\section{Momento temporal de la apertura del procedimiento}

El momento temporal de la apertura del procedimiento se encuentra íntimamente relacionado con la finalidad esencial atribuida al mismo. Como ha quedado señalado, nuestra Ley se decanta por la finalidad solutorioconservativa. Ello exige buscar el difícil equilibrio entre garantizar los derechos de los acreedores a ejercitar sus acciones de ejecución singular con la conveniencia de adelantar en el tiempo la declaración de concurso, a fin de evitar que el deterioro del estado patrimonial impida o dificulte las soluciones más adecuadas para satisfacer a los acreedores. 
Para conseguir ese objetivo, la Ley impone al deudor la obligación de solicitar la declaración de concurso dentro de los dos meses siguientes a la fecha en que hubiese conocido o debido conocer su estado de insolvencia. A esos efectos, y salvo prueba en contrario, se presume que el deudor ha conocido su estado de insolvencia cuando haya acaecido alguno de los hechos que pueden servir de fundamento a una solicitud de concurso necesario conforme al apartado 4 del artículo 2 LC (artículo 5 LC). El incumplimiento del deber de solicitar la apertura del concurso lleva aparejadas consecuencias negativas para el deudor. Así, en ese caso, no puede presentar propuesta anticipada de convenio (artículo 105.1.6. ${ }^{\circ} \mathrm{LC}$ ) y se presume que hubo dolo o culpa grave a efecto de la calificación del concurso (artículo 165.1 LC).

También se prevé el otorgamiento al crédito del acreedor instante, que no tenga el carácter de subordinado, la condición de privilegiado general hasta la cuarta parte de su importe (artículo 91.6 LC). Es cierto que esta medida ha sido criticada por considerar que puede motivar solicitudes apresuradas de concurso ${ }^{5}$, aunque, personalmente, me parece equitativo que se recompense a quien realiza un acto en interés de los demás acreedores, arriesgándose, en caso de desestimación de la solicitud, a una condena en costas e, incluso, a una reclamación de daños y perjuicios del deudor (artículo 20.1 LC) ${ }^{6}$.

Igualmente, con el objeto de anticipar el momento de apertura del procedimiento concursal, el legislador permite - por tanto, constituye una mera facultad, no una obligación - que el deudor solicite la declaración de concurso en la fase previa a la insolvencia, en la llamada situación de «insolvencia inminente».

A los acreedores no se les atribuye esa facultad. Como apunta L. Fernández del $\mathrm{Pozo}^{7}$, la legislación comparada suele reservar la iniciativa al deudor en exclusividad. La solución es razonable; lo contrario supondría una injerencia injustificada en el principio de libre empresa.

La propia Ley concursal - en el artículo 2.3 - define la situación al decir que «se encuentra en estado de insolvencia inminente el deudor que prevea que no podrá cumplir regular y puntualmente sus obligaciones».

\footnotetext{
5 En esa línea, Alonso Lesdesma, C. «La clasificación de los créditos en el concurso», en Estudios sobre el Anteproyecto de Ley Concursal de 2001, dirigido por GARCÍA Villaverde, R., Alonso Ureba, A. y Pulgar Ezquerra, J., Madrid, 2002, p. 195, y Cerdá Albero, F. y SAncho Gargallo, I., en Quiebras y Suspensiones de pagos: claves para la reforma concursal, Barcelona, 2001, pp. 99 y 100.

${ }^{6}$ En ese sentido, puede verse GARRIDO, J.M., «La graduación de créditos», en la Reforma de la Legislación Concursal, cit., pp. 237 y 238.

7 «Sobre la preconcursalidad y la prevención de la insolvencia», en la Reforma de la Legislación Concursal, cit., p. 22.
} 
Este supuesto se diferencia del anterior en que se trata de una previsión de insolvencia y en que se añade el requisito de la puntualidad, con lo que se contempla la simple previsión de incumplimiento, la previsión de cumplimiento irregular y la previsión de cumplimiento regular, pero con retraso.

El problema que plantea la insolvencia inminente es su prueba. No será fácil para el deudor probar la previsión de insolvencia futura ni para el juez comprobar la previsión, y más teniendo en cuenta que los documentos contables de presentación obligatoria en virtud de lo señalado en el artículo 6 de la Ley Concursal, informan sobre el pasado y no expresamente sobre el futuro ${ }^{8}$.

\section{Novedades en la estructura orgánica del concurso: simplificación de la misma y creación de los Juzgados de lo Mercantil}

La Ley, siguiendo la tendencia del ámbito comparado, opta por la simplificación de los órganos concursales que actúan en el procedimiento. Sólo el juez y La administración concursal constituyen órganos necesarios en el mismo. La junta de acreedores únicamente habrá de constituirse en la fase de convenio, cuando no se haya aprobado por el sistema de adhesiones escritas una propuesta anticipada.

En la nueva Ley la estructura orgánica del concurso se asienta sobre dos órganos: El juez y la administración concursal.

La competencia para conocer del procedimiento corresponde a los nuevos Juzgados de lo Mercantil. Se atribuye al juez del concurso jurisdicción exclusiva y excluyente en aquellas materias que se consideran de especial trascendencia para el patrimonio del deudor, aunque sean de naturaleza social, por considerar que su dispersión quebranta la necesaria unidad procedimental y de decisión. Además, el propio texto legal concede también al juez del concurso amplia discrecionalidad en el ejercicio de sus competencias, lo que contribuye a facilitar la flexibilidad del procedimiento y su adecuación a las circunstancias de cada caso.

Por su parte, la administración concursal, que sustituye a los síndicos, se regula conforme a un modelo totalmente diferente del anterior y se opta por un órgano colegiado en cuya composición se combina la profesiona-

8 Una crítica a lo previsto en la Ley Concursal puede verse en Rojo, A., «La reforma del Derecho Concursal español», en La Reforma de la Legislación concursal, cit., pp. 113-117. Considera que el problema temporal ha quedado sin solución, BELTRÁn E., en «Los presupuestos del concurso, publicado en Anales (V), 2002-2003, Centro de Investigación y desarrollo del Derecho Registral Inmobiliario y Mercantil, Barcelona, 2004, pp. 91 y ss. También en «El problema del coste del concurso de acreedores: coste de tiempo y coste económico», en $L a$ Reforma de la Legislación concursal, cit, pp. 323 y ss. 
lidad en aquellas materias de relevancia para todo concurso - la jurídica y la económica - con la presencia representativa de un acreedor que sea titular de un crédito ordinario o con privilegio general, que no esté garantizado. Las únicas excepciones al régimen de composición de este órgano vienen determinadas por la naturaleza de la persona del concursado (cuando se trate de entidad emisora de valores cotizados en bolsa, empresa de servicios de inversión, entidad de crédito, o aseguradora), o por la escasa importancia del concurso, en cuyo caso el juez podrá nombrar un solo administrador, de carácter profesional.

En la nueva Ley Concursal, la obligación principal de la administración concursal es la elaboración de un informe, que comienza con el examen de la documentación presentada por el deudor y que finaliza con una exposición motivada sobre la situación patrimonial de éste. Además, al informe ha de unirse documentación complementaria y debe presentarse en un plazo breve, con el objeto de no retrasar la tramitación. A continuación nos referiremos a todos esos extremos.

El informe de la administración concursal - según prevé el artículo $75.1 \mathrm{LC}$ - ha de contener:

1. Análisis de los datos y circunstancias del deudor expresados en la memoria a que se refiere el número $2 .^{\circ}$ del apartado 2 del artículo 6 LC.

El número 2. ${ }^{\circ}$ del apartado 2 del artículo 6 se refiere a la solicitud de concurso voluntario y dispone que a la solicitud se han de acompañar los siguientes documentos: «La memoria expresiva de la historia económica y jurídica del deudor, de la actividad o actividades a que se hayan dedicado durante los tres últimos años y de los establecimientos, oficinas y explotaciones de que sea titular, de las causas del estado en que se encuentre y de las valoraciones y propuestas sobre la viabilidad patrimonial». En caso de concurso necesario, el juez en el auto de declaración de concurso ha de realizar requerimiento al deudor para que presente, en el plazo de 10 días a contar desde la notificación del auto, los documentos enumerados en el artículo 6.

2. ${ }^{\circ}$ Estado de la contabilidad del deudor y juicio sobre la misma, es decir, sobre las cuentas, estados financieros, informes y memoria a que se refiere el apartado 3 del artículo 6 LC.

El apartado 3 del artículo 6 prevé que si el deudor está legalmente obligado a llevar contabilidad, con la solicitud de declaración de concurso, ha de acompañar:

$\ll 1 .^{\circ}$ Cuentas anuales y, en su caso, informes de gestión o informes de auditoría correspondientes a los tres últimos ejercicios. 
2. ${ }^{\circ}$ Memoria de los cambios significativos operados en el patrimonio con posterioridad a las últimas cuentas anuales formuladas y depositadas y de las operaciones que por su naturaleza, objeto o cuantía excedan del giro o tráfico ordinario del deudor.

3. ${ }^{\circ}$ Estados financieros intermedios elaborados con posterioridad a las últimas cuentas anuales formuladas y depositadas y de las operaciones que por su naturaleza, objeto o cuantía excedan del giro o tráfico ordinario del deudor.

4. ${ }^{\circ}$ En el caso de que el deudor forme parte de un grupo de empresas, como sociedad dominante o como sociedad dominada, acompañará también las cuentas anuales y el informe de gestión consolidados correspondientes a los tres últimos ejercicios sociales y el informe de auditoría emitido en relación con dichas cuentas, así como una memoria expresiva de las operaciones realizadas con otras sociedades del grupo durante el mismo período».

Si el deudor no ha presentado las cuentas anuales correspondientes al ejercicio anterior a la declaración de concurso, han de ser formuladas por la administración concursal, con los datos que puedan obtener de los libros y documentos del deudor, de la información que éste le facilite y de cuanta otra obtenga en un plazo no superior a quince días.

3. ${ }^{\circ}$ Memoria de las principales decisiones acordadas y de las actuaciones ejecutadas por la administración concursal.

Además, al informe, la administración concursal han de unirse - tal como exige el artículo 75.2 LC - la siguiente documentación complementaria:

1..$^{\circ}$ El inventario de la masa activa, que, debe contener la relación y el avalúo de los bienes y derechos que componen el patrimonio del deudor el día anterior al de la emisión de su informe.

2. ${ }^{\circ}$ La lista de acreedores, que comprende una relación de acreedores incluidos, otra de los excluidos y una tercera en la que se mencionan los créditos contra la masa devengados y pendientes de pago. Para la elaboración de la lista, los administradores deben tomar en consideración la documentación del concursado, aunque para mayor garantía de los acreedores, la Ley prevé un sistema de comunicación a través del cual éstos solicitan el reconocimiento de sus créditos. Una vez transcurrido el plazo concedido para comunicación - un mes a contar desde la última de las publicaciones obligatorias de la declaración judicial de concurso-, la administración concursal procede a elaborar la lista.

3. ${ }^{\circ}$ En su caso, el escrito de evaluación de las propuestas de convenio que se hubieran presentado. Es posible que concurran tanto pro- 
puestas anticipadas, que se pueden presentar desde que se solicita el concurso, como ordinarias, que pueden presentarse desde que transcurre el plazo de comunicación de créditos hasta la finalización del plazo de impugnación del inventario y la lista de acreedores.

El informe debe concluir con una exposición motivada de la situación patrimonial del deudor y de cuantos datos y circunstancias pueden ser relevantes para la tramitación del concurso (artículo 75.3 LC).

Respecto al plazo de presentación, cabe apuntar que los administradores concursales deben presentar el informe en el plazo de dos meses, contados desde la fecha en que se produzca la aceptación de dos de ellos o, en su caso, del administrador único (artículo 74.1 LC). Este plazo puede ser prorrogado por el juez, por tiempo no superior a un mes, siempre que la administración concursal lo solicite antes del vencimiento del plazo inicial de dos meses y acredite que concurren circunstancias extraordinarias (artículo 74.2 LC). La contravención de esta obligación es sancionada por la Ley —en el artículo 74.3 LC - con especial rigor. En efecto, el texto legal prevé que si los administradores concursales no presentan el informe dentro del plazo, además de la responsabilidad (artículo 36 LC) y de la causa de separación (artículo 37 LC) en que hayan podido incurrir, pierden el derecho a la remuneración fijada por el juez, por lo que, en su caso, deben devolver a la masa todas las cantidades percibidas. Contra la resolución judicial que acuerde la sanción pueden interponer recurso de apelación.

Tema más complejo, que requiere aunque sea unas breves consideraciones es el relativo a la conveniencia o no de los recientemente creados juzgados de lo mercantil.

Resulta paradójico que el Decreto de Unificación de Fueros de 1868 suprimiese los Tribunales de Comercio por no tener razón de ser y que en la actualidad exista un estado de opinión muy generalizado que considera que la especialización de los juzgados en materia mercantil constituye una realidad incuestionable; tanto es así que en el punto cuarto del Pacto de Estado para la Reforma de la Justicia, firmado el 28 de mayo de 2001, se dice que: «Se avanzará en el diseño de Juzgados especializados en materia mercantil».

Ahora bien, también es cierto que voces autorizadas ${ }^{9}$ han señalado que la necesidad de especialización es perfectamente cuestionable y que esta

9 Fundamentalmente, DíEz-PicAzo, I., en «Los Juzgados de lo Mercantil», en La Reforma de la Legislación Concursal, cit., pp. 138 y EIZAGUiRRE, J.M., en «Los Juzgados de lo Mercantil: un atentado contra la seguridad jurídica», en La Ley $n .^{\circ} 5648$, de 5 de noviembre de 2002). 
innovación legislativa presenta importantes problemas adjetivos; principalmente, cuestiones de competencia, en cuanto toda especialización genera necesariamente complejidad en las normas competenciales de cualquier sistema de justicia, e impide acumular acciones, procesos y reconvenir cuando una de las acciones entre dentro de la competencia de los Juzgados de lo Mercantil y la otra, en el ámbito de la competencia de los Juzgados de Primera Instancia. También se ha apuntado que la creación de tribunales específicamente mercantiles puede dar lugar a una concentración de poder en pocas manos y que desde la perspectiva coste-beneficio sería mejor destinar los recursos públicos invertidos en la especialización en otras necesidades de la Administración de Justicia.

En apoyo de los nuevos juzgados especializados dentro del orden jurisdiccional civil se ha apuntado que, con la especialización, se pueden alcanzar efectos beneficiosos, como los obtenidos con la introducción de magistrados especialistas en los Juzgados Contencioso-Administrativos, siempre que se tomen medidas adecuadas para la formación de estos jueces, se eviten los riesgos de la concentración de poder y se realice la pertinente dotación presupuestaria, de la que, en buena medida, ha de depender el éxito o el fracaso de los nuevos juzgados ${ }^{10}$.

Tampoco cabe obviar la referencia a la cuestión de lo inadecuado del nombre, dado que ni todas las materias mercantiles se han residenciado en ellos, ni todas las materias que les son atribuidas son mercantiles. Parece que el germen de la idea de crear Juzgados de lo Mercantil se encuentra en la necesidad de crear Juzgados de lo Concursal, aunque como el número de procedimientos concursales no justificaba la creación de estos nuevos juzgados en la mayoría de las provincias españolas, el legislador ha decidido justificar su existencia dándoles más competencias: las previstas en el párrafo 2. ${ }^{\circ}$ del artículo 86 ter de la LOPJ, que se concretan básicamente en las siguientes materias: Competencia Desleal, Propiedad Industrial, Propiedad Intelectual, Publicidad, Sociedades Mercantiles y Cooperativas, Transportes, Derecho Marítimo (no Derecho Aeronáutico) y Condiciones Generales de la Contratación. Y es que como se indica en la Exposición de Motivos de la Ley Orgánica para la reforma Concursal, el criterio seguido para la atribución de materias no responde a directrices dogmáticas preestablecidas, sino a un criterio pragmático. Concretamente, se señala en este punto en la norma referida que: «Se parte así de unas bases iniciales prudentes que habrán de desarrollarse progresivamente en los años venideros, de acuerdo con la experiencia que se vaya acumulando».

10 En esa línea, Cordón Moreno, El Proceso Concursal, Pamplona, 2003, p. 42 y RoDRíguez San Vicente, M., «Los Juzgados de lo Mercantil», en Estudio sistemático de la Ley 22/2003 y de la Ley 8/2003, para la Reforma Concursal, dirigido por GARCía VILLAverde, R., Alonso Ureba, A. y Pulgar EzQuerra, J., Madrid, 2003, p. 163. 
Con ello, amplísimos campos del Derecho Mercantil siguen siendo competencia de los Juzgados de Primera Instancia. A título de ejemplo, cabe mencionar materias como la compraventa mercantil, el préstamo mercantil, el leasing, el factoring, la franquicia, los contratos bancarios y bursátiles, el seguro o los conflictos derivados de la emisión de documentos cambiarios.

Respecto a la Junta, como ha quedado señalado, nuestra Ley Concursal, en consonancia con la orientación del Derecho Concursal más reciente, se inclina por el fortalecimiento de otros órganos (Juez y Administración Concursal) y opta por una notable reducción de su ámbito de atribuciones ${ }^{11}$. En la normativa precedente, en el ámbito de la quiebra, las funciones principales de la Junta, que era uno de los órganos necesarios en el procedimiento, eran el nombramiento de los síndicos, el examen, el reconocimiento y la graduación de los créditos reconocidos y la discusión y, en su caso, aprobación de cualquier propuesta de convenio. En cambio, en la actual, la Junta aparece como órgano no necesario: su constitución aparece supeditada a la apertura de la fase de convenio. En ese caso, siguiendo la orientación marcada por la Ley de Suspensión de Pagos, se celebrará la Junta para desempeñar su función, que no es otra que la deliberación y la votación del convenio.

La intervención del Ministerio Fiscal se limita, fundamentalmente, a la sección sexta, de calificación del concurso, cuando proceda su apertura. En ese caso, una vez unido el informe de la Administración Concursal, se le ha de dar traslado del contenido de la Sección para que emita dictamen en el plazo de diez días. El juez, atendidas las circunstancias, puede acordar la prórroga de dicho plazo por un máximo de diez días más. Si el ministerio público no emite dictamen en ese plazo, seguirá su curso el proceso, entendiéndose que no se opone a la propuesta de calificación (artículo 169.2 LC). Junto a lo anterior, destacar que debe ser oído por el juez antes de resolver una cuestión de competencia por declinatoria (artículo 12.2 LC) y que debe cumplir los deberes que le impone el artículo 4 LC, derivados de la circunstancia de que en actuaciones por delitos contra el patrimonio y contra el orden socioeconómico se pongan de manifiesto indicios de estado de insolvencia de algún presunto responsable penal y de la existencia de una pluralidad de acreedores. En ese caso, deberá instar al juez penal para que comunique los hechos al juez de lo mercantil competente, con el objeto de comprobar si, respecto del deudor, se estuviese tramitando un procedimiento concursal. Asimismo, instará al juez penal para comunique los hechos también a los acreedores cuya identidad resulte de las actuaciones penales en curso, a fin de que, en su caso, puedan solicitar la declaración de concurso o ejercitar las acciones que les correspondan.

11 Sobre el particular, QuiJano GonZÁleZ, J., «La Junta de Acreedores en el nuevo Derecho Concursal español», en Derecho Concursal, Estudio sistemático de la Ley 22/2003 y de la Ley 8/2003, para reforma concursal, cit, pp. 244 y ss. 


\section{Regulación sistemática de los efectos del concurso}

Se han regulado los efectos del concurso con la intención de facilitar el desarrollo del procedimiento, la continuación de la actividad y la solución concordataria. Es cierto que históricamente se ha considerado que la mayoría de los efectos del concurso constituyen medidas preventivas, que tienen su origen en la presunción de mala fe o peligrosidad del deudor. Sin embargo, no lo es menos que en la actualidad, abandonado el tradicional componente punitivo que se asignaba a la declaración de insolvencia, se observa, y de forma clara en nuestra Ley Concursal, que con la determinación de los efectos se pretende, sobre todo, facilitar el desarrollo del procedimiento y si, es posible, la continuación de la actividad y la satisfacción de los acreedores a través de un convenio.

En ese sentido, cabe destacar que en relación a las facultades patrimoniales del deudor, la Ley convierte la inhabilitación en excepción reservada para los casos de concurso calificado como culpable, con lo que las limitaciones patrimoniales de la declaración de concurso se concretan en la simple intervención o en la suspensión de las mismas (artículo 21 LC); que, como regla general, la declaración de concurso no interrumpe la continuación de la actividad profesional o empresarial que viniera ejerciendo el deudor (artículo 44 LC); que para evitar que por el sólo hecho de la declaración de concurso se produzca la resolución automática de contratos necesarios para la continuación de la actividad, la norma señala que, salvo que una ley lo disponga o permita optar la extinción del contrato en caso de situación concursal, «se tendrán por no puestas, las cláusulas contractuales que establezcan la facultad de resolución o la extinción del contrato en caso de declaración de concurso» (artículo 61.3 LC) (no obstante, si es posible la aplicación de las leyes que dispongan o que expresamente permitan optar o pactar la extinción del contrato en los casos de situaciones concursales o de liquidación administrativa de alguna de las partes (artículo 63 LC): así, por ejemplo, el artículo 1732.3 del Código Civil prevé que el mandato se acaba por la declaración de quiebra (concurso) del mandante o mandatario o el artículo 26. 1, b) de la Ley de Contrato de Agencia, redactado por la Disposición Final vigésima novena de la Ley Concursal, dispone que cada una de las partes de un contrato de agencia pactado por tiempo determinado o indefinido puede dar por finalizado el contrato en cualquier momento, sin necesidad de preaviso, cuando la otra haya sido declarada en concurso); resaltaré también, que para la conservación de la empresa se establecen también fórmulas flexibles para permitir la rehabilitación de contratos de crédito o de adquisición de bienes con precio aplazado, así como la enervación de desahucio en arrendamientos urbanos, afectados por incumplimientos del deudor concursado (artículos 68 a 70 LC). Es decir, se trata de contratos cuya resolución por incumplimiento 
se ha producido antes de la declaración de concurso y que la posibilidad de rehabilitación se concede después de la declaración y en atención a ella.

Incluso se prevé la paralización de las ejecuciones de garantías reales. Y es que después de la reforma, los acreedores con garantía real sobre bienes del concursado afectos a su actividad profesional o empresarial o a una actividad productiva de su titularidad, no podrán iniciar la ejecución o realización forzosa de la garantía hasta que se apruebe un convenio cuyo contenido no afecte al ejercicio de este derecho o transcurra un año desde la declaración de concurso sin que se hubiese producido la apertura de la liquidación (artículo 56.1. I LC).

El fundamento de esta limitación se encuentra en la función prevalentemente conservativa del concurso, por lo que no tratándose de bienes de los que dependa la continuación de la actividad empresarial, desaparece el fundamento de la paralización de la ejecución ${ }^{12}$. Con ello, se pretende respetar la naturaleza propia del derecho real sobre cosa ajena y, al mismo tiempo, que la ejecución separada no impida soluciones que puedan ser convenientes para los intereses del deudor y para el conjunto de los acreedores (Exposición de Motivos, III, de la Ley Concursal).

Es cierto que la solución propuesta no se deduce con claridad del texto legal, dado que el artículo 55 impide toda ejecución después de la declaración de concurso, dejando a salvo únicamente «lo establecido en la propia Ley para los acreedores con garantía real» y que el artículo 56 se refiere a la ejecución de bienes afectos a la actividad empresarial del deudor, pero no contiene norma alguna relativa a la ejecución sobre bienes no afectos. Sin embargo, del itinerario legislativo, se deduce que el legislador no ha querido poner límites a la ejecución de garantías reales más que cuando recaen sobre bienes afectos a la actividad propia del concursado ${ }^{13}$.

Por la misma razón apuntada anteriormente, la Ley extiende el tratamiento de las acciones de ejecución de garantías reales al ejercicio de ciertas acciones con trascendencia real, como son las de recuperación de bienes vendidos en virtud de contratos inscritos en el Registro de Bienes Muebles o los cedidos en arrendamientos financieros formalizados en documento que lleve aparejada ejecución o haya sido inscrito en el referido Registro, así como a las resolutorias de ventas de inmuebles por falta de pago del precio aplazado, aunque deriven de condiciones explícitas inscritas en el Registro de la Propiedad (artículo 56.1. II LC).

12 En ese sentido, Pulgar EzQuerra, J., «El acreedor hipotecario en la nueva legislación concursal», $R D M$, núm. 250, octubre-diciembre 2003, pp. 1449 y ss.

13 Sobre el tema, CuRIEL, F., «Publicidad registral de la situación concursal en el Proyecto de Ley Concursal», publicado en Anales (V), 2002-2003, Centro para la investigación y desarrollo del Derecho Registral Inmobiliario y Mercantil, cit., p. 129 


\section{Revisión del sistema de privilegios}

Uno de los defectos de que adolecía la legislación anterior era el predominio de determinados intereses particulares en detrimento de otros generales y del principio de igualdad de tratamiento de los acreedores.

Por eso, uno de los objetivos pretendidos con la nueva Ley es la drástica reducción de privilegios y preferencias en el concurso. Se considera que el principio de igualdad de tratamiento de los acreedores ha de constituir la regla general del concurso, y que sus excepciones han de ser muy contadas y siempre justificadas.

Las excepciones que la Ley admite son positivas y negativas, en relación con los créditos ordinarios (Exposición de motivos, V, de la Ley Concursal):

Dentro de las primeras, cabe situar a los créditos privilegiados, en su doble modalidad de créditos con privilegio especial y créditos con privilegio general Para evitar la aprobación de leyes futuras en las que se conceda trato privilegiado a ciertos créditos, como sucedió bajo la vigencia de la legislación anterior, se acoge en el texto articulado, concretamente, en el inciso final del párrafo 2. ${ }^{\circ}$ del artículo 89 , un sistema de numerus clausus de los créditos privilegiados, al disponer que: «No se admitirá en el concurso ningún privilegio o preferencia que no esté reconocido en esta Ley (concretamente, en los artículos 90 y 91 de la misma)».

No cabe duda que la reforma, en este punto, debe valorarse de forma positiva y que se ha reducido el número de privilegios, aunque no podemos dejar de señalar que, en esta materia, la Ley ha recibido críticas que cuestionan la adecuada protección de los acreedores ordinarios Entre ellas, destaca la realizada por la profesora $\mathrm{C}$. Alonso Ledesma ${ }^{14}$ en los siguientes términos: «En materia de privilegios, en efecto, aunque se pone mucho énfasis en la drástica reducción de los mismos, lo cierto es que esa reducción no es tan grande ni tan extensa, ni tan importante como a primera vista pudiera parecer, ya que desde el antecedente de la Propuesta de 1995 hasta la culminación del proceso legislativo, se ha ido ampliando el número y extensión de los privilegios; en unos casos por la presión ejercida por determinados intereses y, en otros, por mantener una línea continuista con el pasado carente totalmente de sentido en la actualidad. Así, por ejemplo, se mantienen los privilegios reconocidos a los créditos que, normalmente, tienen un montante más elevado: los de derecho público (Hacienda, Seguridad Social, etc.) lo cual, aunque limitados hasta el cincuenta por ciento de su importe, disminuye sensiblemente las expectativas de cobro de otros acreedores, especialmente, los ordinarios a los que se dice

14 «Delimitación de la masa pasiva: las clases de créditos y su graduación», en Derecho Concursal, Estudio sistemático de la Ley 22/2003 y de la Ley 8/2003, para la reforma concursal, cit., p. 362. 
querer proteger fundamentalmente. $\mathrm{O}$ se crean otros privilegios cuyo reconocimiento resulta discutible (es el caso del atribuido a favor del acreedor instante del concurso) y otros que si bien resultan equitativos aumentan o pueden aumentar sensiblemente la posibilidad de que no cobren otros acreedores (caso de los créditos derivados de responsabilidad civil)».

$\mathrm{Y}$ es que en la actualidad, existe una corriente favorable a reducir o incluso eliminar la preferencia de los créditos públicos. En épocas pasadas, la debilidad de las finanzas estatales y la menor carga impositiva de los ciudadanos podían justificar la existencia del privilegio en aras de la mejor consecución del interés público, pero hoy se pone en duda que el Estado necesite esa tutela para la consecución de sus fines. Es más, su orientación contrasta con la de otros países de nuestro entorno como la de Portugal o Dinamarca, en los que se suprime este privilegio, y con la de Alemania, donde se han eliminado los privilegios tributarios generales, aunque se mantienen las prendas legales que garantizan determinados impuestos.

Dentro de las segundas - de las excepciones negativas - , se encuentran los créditos subordinados, categoría procedente del Derecho norteamericano que introduce el legislador para clasificar aquellos créditos que merecen quedar postergados tras los ordinarios, por razón de su tardía comunicación, por pacto contractual, por su carácter accesorio (intereses), por su naturaleza sancionadora (multas) o por la condición personal de sus titulares (personas especialmente relacionadas con el concursado o partes de mala fe en actos perjudiciales para el concurso). Los titulares de estos créditos carecen de derecho de voto en la junta de acreedores (artículo 122.1.1. ${ }^{\circ} \mathrm{LC}$ ), aunque, en su caso, les vinculará el convenio, quedando afectados por las mismas quitas y esperas establecidas en él para los acreedores ordinarios, si bien los plazos de espera se computarán a partir del íntegro cumplimiento del convenio respecto de los ordinarios. A los acreedores subordinados también se les reconoce la posibilidad de aceptar propuestas alternativas consistentes en convertir sus créditos en acciones, participaciones o cuotas sociales o en créditos participativos (artículo 134.1 LC). En caso de liquidación, no podrán ser pagados hasta que hayan quedado íntegramente satisfechos los ordinarios. El pago de estos créditos se realizará por el orden establecido en el artículo 92 LC y, en su caso, a prorrata dentro de cada número (artículo 158 LC).

\section{Admisión de propuesta anticipada de convenio}

Se ha admitido la llamada propuesta anticipada de convenio, con el objeto de ofrecer un cauce más ágil y rápido de tramitación del mismo. Por este cauce, no sólo no es necesaria la apertura de la fase de convenio (artículo 109.2 LC), sino que para la aprobación del mismo se sigue el sistema de adhesiones, evitándose con ello la celebración de una junta. 
La facultad de presentar propuesta anticipada de convenio se concede sólo al deudor. Sin embargo, es criticable que esta posibilidad no se conceda a todos los deudores sino sólo a aquellos que cumplan los requisitos de merecimiento. Y es que el legislador concibe la propuesta anticipada como un beneficio, cuya concesión está supeditado a una correcta conducta patrimonial; por tanto, no permite acogerse a él al concursado que en el desarrollo de su actividad económica se encontrase o hubiese encontrado en alguno de los casos recogidos en el artículo 105.1 LC, a saber:

1. ${ }^{\circ}$ Haber sido condenado por sentencia firme por delito contra el patrimonio, contra el orden socioeconómico, de falsedad documental, contra la Hacienda Pública, la Seguridad Social o contra los derechos de los trabajadores. En caso de deudor persona jurídica, se dará esta causa de prohibición si hubiera sido condenado por cualquiera de estos delitos alguno de sus administradores o liquidadores, o de quienes lo hubieran sido en los tres años anteriores a la presentación de la propuesta de convenio.

2. ${ }^{\circ}$ Haber incumplido en alguno de los tres últimos ejercicios la obligación de depósito de las cuentas anuales.

3. ${ }^{\circ}$ No figurar inscrito en el Registro mercantil, cuando se trate de persona o entidad de inscripción obligatoria.

4. ${ }^{\circ}$ Haber estado sometido a otro concurso de acreedores sin que a la fecha de la solicitud del que se encuentre en tramitación hayan transcurrido tres años desde la conclusión de aquél.

5. ${ }^{\circ}$ Haber realizado dentro de los tres años anteriores a la fecha de solicitud de concurso alguno de los siguientes actos:

a) Disposición de bienes o derechos a título gratuito que exceda de las liberalidades al uso.

b) Disposición de bienes o derechos a título oneroso a favor de un tercero o de alguna de las personas especialmente relacionadas con el concursado a que se refiere el artículo 93 de la LC, realizada en condiciones que, al tiempo de su celebración, no fueren las normales de mercado.

c) Pago de obligaciones no vencidas.

d) Constitución o ampliación de garantías reales para el aseguramiento de obligaciones preexistentes.

e) Otros actos que hayan sido declarados en fraude de acreedores por sentencia, aunque no haya alcanzado firmeza.

6. ${ }^{\circ}$ Haber incumplido el deber de solicitar la declaración de concurso o haber infringido durante la tramitación de concurso alguno de los deberes u obligaciones que impone la Ley Concursal. 
Si admitida a trámite la propuesta anticipada de convenio, el concursado incurre en causa de prohibición o se comprueba que con anterioridad había incurrido en alguna de ellas, el juez de oficio, a instancia de la administración concursal o de parte interesada y, en todo caso, oído el deudor, debe declarar sin efecto la propuesta y poner fin a su tramitación (artículo 105.2 LC).

El deudor puede presentar una propuesta anticipada desde la solicitud de concurso voluntario o desde la declaración de concurso necesario hasta la expiración del plazo de comunicación de los créditos, lo que se produce en el plazo de un mes a contar desde la última de las publicaciones obligatorias de la declaración de concurso señaladas en el artículo 23 de la LC (artículo 104.1 LC).

Para su admisión a trámite, la propuesta anticipada debe ofrecer una mínima credibilidad; credibilidad que se supedita a que vaya acompañada de adhesiones de acreedores ordinarios o privilegiados, cuyos créditos superen la quinta parte del pasivo presentado por el deudor (artículo 106.1 LC).

El juez competente debe resolver sobre la admisión a trámite de la propuesta anticipada de convenio, sin posibilidad de recurso, en los momentos siguientes, en función de cuándo ha sido presentada la propuesta:

a) Cuando la propuesta anticipada de convenio se presenta con la solicitud de concurso voluntario o antes de la declaración judicial de éste, el juez ha de resolver sobre su admisión en el mismo auto de declaración de concurso.

b) En los demás casos, debe resolver, también mediante auto motivado, dentro de los tres días siguientes al de presentación de la propuesta anticipada.

Si aprecia algún defecto, el juez debe notificarlo al concursado para que en los tres días siguientes a la notificación pueda subsanarlo (artículo 106.2 y 4 LC).

El juez no admitirá a trámite una propuesta de convenio en los casos siguientes - previstos en el artículo 106.3 LC - :

a) Cuando las adhesiones presentadas no superen la quinta parte del pasivo presentado por el deudor.

b) Cuando aprecie infracción legal en el contenido de la propuesta de convenio.

c) Cuando el deudor se encuentre incurso en alguna de las prohibiciones legales.

Si se admite a trámite la propuesta anticipada de convenio, el juez debe remitírsela a la administración concursal para que en un plazo no superior a diez días proceda a su evaluación. En ese plazo, ésta debe evaluar el contenido de la propuesta de convenio en atención al plan de pagos y, en su caso, 
al plan de viabilidad que la acompañen. Si la evaluación es favorable, se unirá al informe de la administración concursal, pero si es desfavorable o contiene reservas, el juez puede dejar sin efecto la admisión de la propuesta anticipada. También puede optar por la continuación de su tramitación, con unión del escrito de evaluación al referido informe de la administración concursal. Contra el auto que resuelve sobre este extremo no cabe recurso alguno (artículo 107 LC). De ese modo, los acreedores cuentan con una opinión técnica sobre el convenio que les ayudará a decidir el sentido de su voto.

Para simplificar y agilizar la tramitación de la propuesta anticipada de convenio, la Ley Concursal no exige que se apruebe en junta de acreedores, sino que opta por el sistema de adhesiones. Con ese objeto, después de la admisión a trámite se abre un plazo para que puedan adherirse a la propuesta aquellos acreedores que lo deseen y que no lo hicieron en el momento de su presentación. Esas adhesiones se pueden efectuar desde la admisión a trámite de la propuesta hasta la expiración del plazo de impugnación del inventario y de la lista de acreedores (artículo 108.1 LC).

Tanto en este caso como en el de tramitación ordinaria del convenio, la Ley Concursal distingue un trámite de verificación de las adhesiones y un trámite de aprobación judicial. La distinción es lógica: primero, una vez finalizado el plazo de adhesiones, el juez verificará si las adhesiones presentadas alcanzan la mayoría legalmente exigida para que se considere aceptada una propuesta anticipada de convenio, para lo que será necesaria, en todo caso, y como regla general, la adhesión de acreedores que titulen créditos por importe, al menos, de la mitad del pasivo ordinario del concurso, considerándose incluidos en el pasivo ordinario del concurso los créditos de los acreedores privilegiados que se hayan adherido a la propuesta (artículo 124 LC). Deberá llevar a cabo ese cometido dentro de los cinco días siguientes a aquel en que finalizase el plazo de impugnación del inventario y de la lista de acreedores si no se hubiesen presentado impugnaciones o, de haberse presentado, dentro de los cinco días siguientes a aquel en que hubiera finalizado el plazo para la revocación de las adhesiones. Si se obtiene la mayoría suficiente para la aprobación del convenio, lo proclamará mediante providencia (artículo 109.1 LC).

A continuación, los acreedores que no se han adherido a la propuesta pueden formular oposición a la aprobación judicial del convenio, en la forma y por las causas que la norma regula al abordar el tema de la tramitación del convenio en junta de acreedores (artículos 128 y ss.), en el plazo de diez días, contado desde el siguiente a la fecha en que el juez dicta la providencia por la que se pone de manifiesto que las adhesiones presentadas alcanzan la mayoría legal para la aceptación del convenio (artículo 128.1 LC). 
Si no se formula oposición, el juez, en los cinco días siguientes al vencimiento del plazo de oposición a la aprobación judicial del convenio, dictará sentencia aprobatoria, salvo que éste sea rechazado de oficio por él por concurrir alguna de las infracciones previstas en el artículo 131 LC.

La sentencia, que se notificará al concursado, a la administración concursal y a todas las partes personadas en el procedimiento y se publicará conforme a lo previsto en los artículos 23 y 24 LC, pondrá fin a la fase común del concurso y, sin apertura de la fase de convenio, aprobará éste con los efectos establecidos en los artículos 133 a 136 LC (artículo 109.2 LC).

De esa forma, la nueva Ley, con la regulación de la propuesta anticipada, permite que el convenio se apruebe durante la fase común del concurso, con una notoria economía de tiempo y de gastos respecto a los anteriores procedimientos concursales (Exposición de Motivos, VI, párrafo 3. ${ }^{\circ}$, de la Ley Concursal).

\section{Agilización de la fase de liquidación}

La liquidación es siempre una solución subsidiaria, que opera cuando no se alcanza o se frustra el convenio. La liquidación, como no puede ser de otra manera, tiene por objeto la enajenación del patrimonio del deudor para ser repartido entre los acreedores. En este punto, merece ser destacado que se ha tratado de agilizar la fase de liquidación, imponiendo a los administradores concursales un plazo máximo para su conclusión. En efecto, el plan de liquidación, que constituye la primera opción para llevar a cabo la realización de los bienes y derechos integrados en la masa activa del concurso, siempre que sea aprobado por el juez, deberá ser elaborado por los administradores concursales dentro de los quince días siguientes al de la notificación de la resolución de apertura de la fase de liquidación a la administración concursal, plazo que podrá ampliarse a treinta si por justificarlo la complejidad del concurso se acordarse la prórroga del inicial. Por otra parte, se impone también a los administradores concursales la obligación de finalizar la liquidación en el plazo de un año, a contar desde la apertura de la fase de liquidación. Si incumplen esta obligación, cualquier interesado puede solicitar al juez la separación de los administradores concursales y el nombramiento de otros nuevos. El juez, previa audiencia de los administradores concursales, acordará la separación si no existe causa que justifique la dilación; separación que conlleva, además, la pérdida del derecho a la retribución (artículo 153 LC).

Además, incluso en las operaciones de liquidación se manifiesta la finalidad conservativa del concurso, al procurar la Ley que la venta de las unidades productivas se realice como un todo. En ese sentido, el artículo 148 de la LC señala que «siempre que sea posible, en el plan (de liquidación) se 
debe contemplar la enajenación unitaria del conjunto de los establecimientos, explotaciones y cualquiera otras unidades productivas de bienes y servicios del concursado o de algunos de ellos».

\section{Regulación de un procedimiento abreviado}

Se ha previsto la posibilidad de utilizar un procedimiento abreviado en los concursos de escasa entidad. Concretamente, su ámbito de aplicación se supedita a que el deudor sea una persona natural o persona jurídica que, conforme a la legislación mercantil, esté autorizada a presentar balance abreviado, a que la estimación inicial de su pasivo no supere 1.000 .000 de euros y a la decisión judicial, ya que, aunque concurran los dos requisitos anteriores, la decisión de admitir o no el procedimiento simplificado queda al arbitrio del juez (artículo 190.1 LC).

En cuanto a su régimen jurídico, se aplican las normas generales con las dos siguientes particularidades:

1. La reducción de plazos: con carácter general, los plazos se reducen a la mitad (con redondeo al alza si se trata de número impar), salvo aquellos que el juez acuerde mantener para el mejor desarrollo del procedimiento. En todo caso, el plazo para la presentación del informe de la administración concursal será de un mes a contar desde la aceptación de su cargo y sólo podrá autorizarse una prórroga por el juez del concurso no superior a 15 días (artículo 191.1 LC).

2. ${ }^{a}$ La simplificación de la administración concursal: la administración concursal estará integrada por un único miembro (que deberá ser abogado, auditor de cuentas, economista o titulado mercantil con experiencia profesional de, al menos, cinco años de ejercicio efectivo), salvo que el juez acordase lo contrario, por apreciar motivos especiales que lo justifiquen (artículo 191.2 LC). 